\title{
COMPLICATIONS OF CHICKENPOX IN BULGARIA - DATA FROM A SINGLE-CENTER EXPERIENCE
}

\author{
M. Popov ${ }^{1}$, S. Antonov ${ }^{2}$, V. Velev ${ }^{1}$, T. Tcherveniakova ${ }^{1}$, N. Yancheva ${ }^{1}$ \\ ${ }^{1}$ University Hospital „Prof. Ivan Kirov”, Medical University - Sofia, Bulgaria \\ ${ }^{2}$ Department of Radio-communication and Video Technology, Technical University - Sofia, Bulgaria
}

\begin{abstract}
Primary Varicella zoster infection (chickenpox) in childhood is a common benign disease. The predominance of uncomplicated cases in children often overshadows the rarer cases of complicated severe course of the disease. Objective: To study the complications of primary chickenpox in hospitalized patients for a period of one year. Materials and Methods: 122 patients with complicated primary chickenpox with an average age of 18.6 years; 57 males (46.7\%) and 64 females (53.3\%), were hospitalized at the University Hospital of Infectious and Parasitic Diseases "Prof. Iv. Kirov" in the period January - December 2019. Results: The bacterial infections of the skin and soft tissues comprised the largest relative frequenchy - they occurred in 74 (60.6\%) of the patients; followed by pneumonia - in 31 (25.4\%) patients, and a combination of pneumonia and pustulation in $10(8.2 \%)$ patients. Cerebelitis was observed in 1 (0.8\%) patient. One of the patients developed hepatitis, purulent arthritis and acute enteritis. We also report the death of one patient. Conclusions: We registered a relatively high proportion of hospitalizations, especially in young children and adults. Regarding the type of complications, we do not describe significant differences compared to other authors. Although in most cases primary chickenpox is a self-limiting disease, complications are more common in the countries where there is no vaccine.
\end{abstract}

Key words: chickenpox, complications, pneumonia, varicella vaccine

Corresponding author: Valeri Velev, PhD, Hospital "Iv. Kirov", 17 "Akad. Geshov" Blvd., 1431, Sofia, Bulgaria, velev_md@abv.bg

RECEIVED: 10 September 2020; LAST REVISED: 5 January 2021; ACCEPTED: 10 January 2021

\section{INTRODUCTION}

T he infection with the varicella zoster virus $(\mathrm{VZV})$ can take the form of two diseases - primary varicella (chickenpox) or secondary one - herpes zoster infection. The causative agent of VZV is a member of the human herpes viruses and belongs to the Simplex virus genus. Chickenpox is a highly contagious disease characteristic mainly of childhood and having usually a favourable progression, being self-limiting. In adults, in immunocompro- mised patients, or in children under 1 year of age, the disease may take a severe course with a fatal outcome [1-3].

$A$ vaccine against $V Z V$ is available in Bulgaria only as of this year unlike most countries of the European Union and the European Economic Area (EU/EEA) [4]. Therefore, the epidemiology of chickenpox in Bulgaria has some specifics. It is common, especially in childhood, and in the last decades the incidence has been almost constant. According to data of the Ministry of Health for the last three years -2017 , 
2018,2019 - the cases were respectively 24,970 , 23,402 and 30,183 within a population of $6,951,482$ in December $2019[5,6]$. More than $10 \%$ of the adult population in Bulgaria is seronegative, which shows a high sensitivity of the more vulnerable part of the population and is a precondition for more frequent complications and subsequent hospitalizations $[4,7]$.

The aim of this study was to investigate the epidemiology of complications of primary chickenpox in hospitalized patients for a period of one year at a clinical center for infectious diseases.

\section{MATERIALS AND METHODS}

This is a prospective study of 122 patients hospitalized at the University Hospital for Infectious and Parasitic Diseases "Prof. Iv. Kirov", Sofia, with complicated primary chickenpox during the period January-December 2019. The term "complicated" applied to any chickenpox patient who needed hospitalization. Primary meningoencephalitis was reported with altered consciousness and/or changes in the cerebrospinal fluid (CSF); cerebral ataxia was considered if there were any ataxia symptoms. Hepatitis was determined in cases with an increase of at least 150\% in liver transaminases. Secondary bacterial infection was reported when a bacterial pathogen was isolated from the site of infection, from the bloodstream, and/or when surgical treatment of the lesions was required. To diagnose pneumonia data from X-rays of the lung were required, together with increased white blood cell count, increased erythrocyte sedimentation rate (ESR) and/or C-reactive protein. Enteritis was diagnosed in cases with a minimum of 3 unstable bowel movements per day without isolation of faecal pathogens. Demographic data were also analyzed - gender, age, epidemiological history and previous chronic diseases.

The study was conducted in compliance with the Declaration of Helsinki 2000 and was approved by the Ethics Committee of the hospital. Excel 2016 and Matlab software applications were used for statistical analysis; $\mathrm{P}$ values $<0.05$ were considered statistically significant.

\section{RESULTS}

The total number of patients with primary chickenpox in Sofia over the year of investigation is 6243. 122 $(1.9 \%)$ patients with a mean age of 18.6 years were hospitalized with primary chickenpox at our hospital, of which 57 (46.7\%) were males and 64 (53.3\%) were females. We assumed that the lost for follow-up due to referrals to other clinics were minimal. There are only two other infectious disease units in the city of Sofia - one serving the population from the regions around the city and the other is mainly for military personnel. Most of the hospitalized patients were respectively from the city of Sofia $-83.6 \%$, and $7.4 \%$ were from the area around Sofia. The age distribution and the epidemiological data of the patients are described in Table 1. A survey among the patients or their parents found a contact with an infected person in 91 patients $(74.6 \%)$; and in $73.8 \%$ of cases that contact was with a patient with primary chickenpox, and in $0.8 \%$ of cases - with a patient with herpes zoster. Data of visits to organized children's groups immediately before the onset of symptoms were documented for the children aged from 1 to 7 years as follows $-16.3 \%$ of the children under 3 years and $28.4 \%$ of the children from 4 to 7 years.

The disease shows several seasonal peaks - December-February followed by May-June. Decline in the incidence of the disease is observed in late summer and early autumn.

In our study, all patients exhibited the common symptoms of the infection - fever and a typical rash syndrome. All of them had complications that required hospital treatment (Table 2). Ninety-two (92) of the patients $(75.4 \%)$ received etiological treatment with acyclovir, and $38(31.2 \%)$ needed intravenous administration of the drug for at least 5 days.

Table 1. Rate of hospitalizations by age groups

\begin{tabular}{|c|c|c|}
\hline Age group & $\mathrm{N}$ & $\%$ \\
\hline <1 years & 7 & 5.7 \\
\hline 1-3 years & 22 & 18.3 \\
\hline 4-7 years & 28 & 22.9 \\
\hline 8-15 years & 8 & 6.5 \\
\hline $16-18$ years & 2 & 1.6 \\
\hline 19-30 years & 23 & 18.8 \\
\hline$>30$ years & 32 & 26.2 \\
\hline
\end{tabular}

Table 2. Type and rates of complications in hospitalized patients

\begin{tabular}{|l|c|c|}
\hline Complications & N & $\%$ \\
\hline Skin and soft tissue infections & 74 & 60.6 \\
\hline Pneumonia & 31 & 25.4 \\
\hline Pneumonia + Skin and soft tissue infections & 10 & 8.2 \\
\hline Enteritis & 3 & 2.4 \\
\hline Hepatitis & 1 & 0.8 \\
\hline Encephalitis/cerebellitis & 1 & 0.8 \\
\hline Pyogenic arthritis & 1 & 0.8 \\
\hline Death & 1 & 0.8 \\
\hline
\end{tabular}


The bacterial infections of the skin and soft tissues, occurring in $74(60.6 \%)$ of patients, held the largest relative share, and in most cases these infections were presented as disseminated pustules on the skin or local cellulite, less often phlegmons. In 3 patients $(2.5 \%)$, the skin infection was presented as phlegmon and required surgery. $S$. aureus was isolated from the site of soft tissue infection in 5 patients(4.1\%). The second most frequent complication was pneumonia - in 31 patients $(25.4 \%)$. In most cases, they were accompanied by a characteristic X-ray image of the lungs and inflammatory changes in the peripheral blood counts.

We observed leukocytosis combined with increased ESR and C-reactive protein in nearly $1 / 4$ of our hospitalized patients. In 20 of these patients (16.4\%), H. influenzae was isolated from throat secretions, and in 1 patient $(0.8 \%)-S$. pneumonie. We registered pneumonia with pustulation in 10 patients $(8.2 \%)$. Cerebellitis was observed in 1 patient $(0.8 \%)$. One patient developed hepatitis with elevated AST (104 $\mathrm{UI} / \mathrm{I})$ and ALT (311 IU/I), purulent arthritis and acute enteritis with diffuse diarrhea syndrome. A 38-yearold patient with primary chickenpox and concomitant diabetes mellitus died of severe pneumonia.

\section{DISCUSSION}

The aim of the study was to assess the complications in patients with primary chickenpox in our hospital, as well as some epidemiological and demographic aspects.

Most of the hospitalized patients, especially the children, had an epidemiological history of contact with chickenpox patients. Our data on the seasonal distribution of the infection are in line with the data from the available literature for the country, indicating mainly winter-spring seasonality of the disease. The winter-spring seasonality of chickenpox in Central Bulgaria was described, as well as the high percentage of hospitalizations in Northern Bulgaria in June and July in the period 2003-2007 [7-9].

According to most authors complications may develop in $2-6 \%$ of the cases of primary chickenpox [3]. Several studies by European authors describe a hospitalization rate of $1.3-4.5$ per 100,000 people [10-13]. This indicates a relatively higher frequency of hospitalizations in our study. The highest hospitalization rates due to complicated chickenpox was described in the age groups under 1 year and between 5 and 9 years in a German study before the start of mass immunization [14]. In our study, the highest incidence of complications, respectively hospitalization rates, was observed in early childhood (1-3 and 4-7 years), but unlike the studies in countries with widespread vaccine use, we also had a significant number of hospitalized adult patients aged between 19 and 30 years and over 30 years. That is a relatively high morbidity rate and serious complications are observed in people of active age.

An overview of several reports of chickenpox complications in Central and Eastern Europe has recently been published [15]. The data for Eastern Europe show that the annual incidence ranges from $164 / 100,000$ in Latvia in 2010 to $575.9 / 100,000$ in Poland in 2014. Hospitalization cases with severe complications and direct costs of $\$ 4.2$ million were described. About 4,200 people had died [15]. Regarding the type of complications in the course of chickenpox we did not find in our study any significant differences to those reported by these authors. Usually, the majority of patients who develop complications are immunocompetent and without concomitant diseases [11, 12, 15]. No deaths from complicated chickenpox were reported in the summary reports. A more recent national report from Lithuania reported one case of chickenpox-related death in 2016 [16]. We also had such a case in our study.

Although in most cases chickenpox is a mild and self-limiting disease, there are more complications and consequently more hospitalizations in countries without vaccination. It is possible even to have lethal cases. Monitoring in the EU/EEA and the US shows a rapid reduction in the incidence and complications of chickenpox in countries where routine vaccination has been introduced. The incidence is reduced in both infants less than 12 months of age and in adults, which suggests an indirect effects of the vaccine even in age groups for which it is not recommended [17, 18]. The United States and Germany have reported improved efficacy of the vaccine when it is administered in two doses instead of one [19, 20]. The concerns that mass immunization in children may temporarily increase the incidence of chickenpox or herpes zoster in adults are not justified [4]. The WHO recommends vaccination of children when the disease appears to be an important public health and socio-economic problem. As recommended by the European Center for Disease Control (ECDC), a vaccination program is needed after a detailed epidemiological and socio-economic snapshot in the country, as well as a possibility of high coverage through vaccination (ECDC) $[4,15]$.

It is recommended that two doses of the vaccine be given to children up to 12 months of age. Adolescents and adults with impaired immunity, as well as specific categories of people with severe morbidity, can also be immunized $[17,18]$. 
The data from Eastern European countries show that only in Latvia children between 12 and 15 months of age receive a single-dose universal chickenpox vaccine [15]. In the Czech Republic, Estonia, Hungary, Poland, Slovenia, Russia, the vaccine is recommended for special categories of people at high risk of infection only $[17,18]$.

Globally, two-dose vaccination was shown to be more effective than single-dose vaccination (92\% vs. $81 \%)$. Moreover, there is evidence that two-dose vaccination may be more effective in preventing outbreaks $[18,20]$. As there is currently no officially published international guidelines, the recommendations of the Advisory Committee on Immunization Practices (ACIP) of the US Center for Disease Control (CDC) are largely followed. The first recommendations were published in 1995 and updated in 2010. They recommended that two doses of $0.5 \mathrm{ml}$ vaccine be administered subcutaneously to children over 12 months of age, adolescents, and immunocompromised adults [18-20].

\section{CONCLUSION}

Bulgaria is one of the last EU countries to introduce an optional chickenpox vaccine in its immunization schedule. The vaccine is available on the Bulgarian market since 2020, but unfortunately its cost is not covered by the national health insurance system and must be paid by the parents. This fact, together with the crisis caused by COVID-19, can significantly compromise mass vaccination.

Disclosure Summary: The authors have nothing to disclose

\section{REFERENCES}

1. Hambleton S. Chickenpox. Curr Opin Infect Dis. 2005; 18(3):235-40.

2. Soman R, Madan S. Chickenpox: docile or deadly? J Postgrad Med. 2013; 59(2):91-2.
3. Vázquez $M$, Cravioto $P$, Galván $F$, et al. Varicella and herpes zoster: challenges for public health. Salud Publica Mex. 2017; 59(6):650-656.

4. WHO position paper. Varicella and herpes zoster vaccines: WHO position paper, June 2014. Wkly Epidemiol Rec. 2014; 89:265-88.

5. Ministry of Health of Bulgaria, NCIPD, Available from: https:// ncipd.org/index.php?lan=bg

6. National Statistical Institute, Bulgaria, Available from: https:// www.nsi.bg/en/node/1125

7. Komitova R, Boev I, Kazakova Z, et al. Varicella complications-could we do more? Arch Dis Childhood. 2014; 99:A308.

8. Gantcheva G. Chickenpox - clinical course, treatment and prevention. Medinfo. 2012; 10:27-32 (article in Bulgarian).

9. Gantcheva G, Doichinova Ts, Simova I, et al. Clinical-laboratory and epidemiological characteristics of chickenpox in the Pleven region. Medinfo. 2008; 10:32-37 (article in Bulgarian).

10. Banadyha N, Rogalskyy I, Komorovsky R. Chickenpox in adults - clinical management. J Infect. 2008; 57(2):95-102.

11. Leonid I, Evelyn L. Primary varicella in an immunocompetent adult. J Clin Aesthet Dermatol. 2009; 2:36-38.

12. Jaeggi A, Zurbruegg RP, Aebi C. Complications of varicella in a defined central European population. Arch Dis Child 1998; 79:472-477.

13. Widgren $\mathrm{K}$, Giesecke J, Lindquist $\mathrm{L}$, et al. The burden of chickenpox disease in Sweden. BMC Infect Dis. 2016; 16: 666.

14. Siedler A, Dettmann M. Hospitalization with varicella and shingles before and after introduction of childhood varicella vaccination in Germany. Hum Vaccin Immunother. 2014; (12): 3594-3600.

15. Mészner Z, Wysocki J, Richter D, et al. Burden of varicella in Central and Eastern Europe: findings from a systematic literature review. Expert Rev Vaccines. 2019; (3):281-293.

16. Sergamumo Užkrečiamosiomis Ligomis Lietuvoje 2016 M. Apžvalga (Incidence of infectious diseases in Lithuania in 2016: overview). Available from: http://www.ulac.It/uploads/ downloads/en_sergamumo_katalogas/2016_en/Sergamumo_apzvalga_2016.pdf

17. Vazquez M, LaRussa PS, Gershon AA, et al. Effectiveness over time of varicella vaccine. JAMA : the journal of the American Medical Association 2004; 291: 851-5.

18. Baxter R, Ray P, Tran TN, et al. Long-term effectiveness of varicella vaccine: a 14-Year, prospective cohort study. Pediatrics 2013; 131: e1389-96.

19. Marin M, Guris D, Chaves S, et al. Prevention of Varicella: Recommendations of the Advisory Committee on Immunization Practices (ACIP), 2007.

20. Seward J, Marin M, Vázquez M. Varicella vaccine effectiveness in the US vaccination program: a review. J Infect Dis . 2008; 197 Suppl 2: S82-9. 